\title{
Room-Temperature Fabricated Thin-Film Transistors Based on Compounds with Lanthanum and Main Family Element Boron
}

\author{
Peng Xiao ${ }^{1}$, Junhua Huang ${ }^{1}$, Ting Dong ${ }^{2}$, Jianing Xie ${ }^{1}$, Jian Yuan ${ }^{1, *}$, Dongxiang Luo ${ }^{3}$ \\ and Baiquan Liu $4,5, *$ \\ 1 School of Physics and Optoelectronic Engineering, Foshan University, Foshan 528000, China; \\ xiaopeng@fosu.edu.cn (P.X.); jamha1212@163.com (J.H.); xiejianingfs@126.com (J.X.) \\ 2 Guangdong Juhua Printed Display Technology Co. Ltd., Guangzhou 510006, China; dongt@tcl.com \\ 3 School of Materials and Energy, Guangzhou University of Technology, Guangzhou 510006, China; \\ Luodx@gdut.edu.cn \\ 4 Institute of Polymer Optoelectronic Materials and Devices, State Key Laboratory of Luminescent Materials \\ and Devices, South China University of Technology, Guangzhou 510640, China \\ 5 LUMINOUS! Center of Excellence for Semiconductor Lighting and Displays, School of Electrical and \\ Electronic Engineering, Nanyang Technological University, Nanyang Avenue, Singapore 639798, Singapore \\ * Correspondence: yuanjian054@163.com (J.Y.); 1.baiquan@mail.scut.edu.cn (B.L.); \\ Tel.: +86-0757-8271-5285 (J.Y.); +86-020-8711-4567 (B.L.)
}

Received: 30 April 2018; Accepted: 5 June 2018; Published: 6 June 2018

\begin{abstract}
For the first time, compounds with lanthanum from the main family element Boron $\left(\mathrm{LaB}_{\mathrm{x}}\right)$ were investigated as an active layer for thin-film transistors (TFTs). Detailed studies showed that the room-temperature fabricated $\mathrm{LaB}_{\mathrm{x}}$ thin film was in the crystalline state with a relatively narrow optical band gap of $2.28 \mathrm{eV}$. The atom ration of $\mathrm{La} / \mathrm{B}$ was related to the working pressure during the sputtering process and the atom ration of $\mathrm{La} / \mathrm{B}$ increased with the increase of the working pressure, which will result in the freer electrons in the $\mathrm{LaB}_{\mathrm{x}}$ thin film. $\mathrm{LaB}_{\mathrm{x}}$-TFT without any intentionally annealing steps exhibited a saturation mobility of $0.44 \mathrm{~cm}^{2} \cdot \mathrm{V}^{-1} \cdot \mathrm{s}^{-1}$, which is a subthreshold swing (SS) of $0.26 \mathrm{~V} /$ decade and a $I_{\text {on }} / I_{\text {off }}$ ratio larger than $10^{4}$. The room-temperature process is attractive for its compatibility with almost all kinds of flexible substrates and the $\mathrm{LaB}_{\mathrm{x}}$ semiconductor may be a new choice for the channel materials in TFTs.
\end{abstract}

Keywords: $\mathrm{LaB}_{x}$; thin film transistors; low temperature; field effect; flexible

\section{Introduction}

The flexible active matrix organic light-emitting diode (AMOLED) displays have been attracting great attention because they have many outstanding advantages such as thin width, lightweight, and superior flexibility [1-3]. As the key part of the AMOLED, thin film transistors (TFTs) with a low temperature process become an inevitable trend in order to match flexible displays.

Over recent decades, amorphous silicon (a-Si) and polycrystalline silicon have been the main choice for channels in TFTs. However, a-Si TFTs has a low mobility of less than $1 \mathrm{~cm}^{2} \cdot \mathrm{V}^{-1} \cdot \mathrm{s}^{-1}$, which is too low to drive high resolution displays $[4,5]$. On the other hand, polycrystalline silicon TFTs possess poor uniformity due to the grain boundary, which limits its application in large-size displays [6,7]. Compared to silicon based TFTs, metal oxide TFTs (e.g., InGaZnO [8-10], InZnO [11-13], and $\mathrm{ZnO}$ [14-16]) have a great potential in flat panel displays because of their high mobility, visible-light transparency, satisfactory uniformity, and low temperature process [17,18]. However, TFTs based on metal oxides are meeting a great challenge of long-term stability. Actually, InGaZnO (IGZO) was the 
most representative among oxide material systems. Since Nomura et al. [19] reported the flexible TFTs based on IGZO, the IGZO has attracted extensive attention. Currently, with the efforts of many scientific researchers, AMOLEDs based on IGZO-TFTs have entered people's life. However, Indium is a rare earth element and is becoming rarer. Therefore, the cost is very expensive. Furthermore, considering the cost and stability, it is necessary to develop some new materials to fabricate TFTs at a low temperature. To develop In-free materials, Alston et al. [20] reported TFTs with a GaSnZnO (GSZO) active layer fabricated below $150{ }^{\circ} \mathrm{C}$. However, the mobility was only $0.14 \mathrm{~cm}^{2} \cdot \mathrm{V}^{-1} \cdot \mathrm{s}^{-1}$. Park et al. [21] reported solution-processed TFTs with an alkali metal doped ZnO active layer, but the $\mathrm{ZnO}$ surface was sensitive to the atmosphere and the device stability was poor. Kim et al. [22] reported TFTs with an Hf doped ZnO active layer, but the electrical performance was poor with a large subthreshold swing $(S S)$ of $1.09 \mathrm{~V} /$ decade and a turn-on voltage $\left(V_{\text {on }}\right)$ of $-7 \mathrm{~V}$. Jiang et al. [23] reported TFTs with an $\mathrm{Al}$ doped $\mathrm{ZnO}$ active layer, but the mobility was only $0.17 \mathrm{~cm}^{2} \cdot \mathrm{V}^{-1} \cdot \mathrm{s}^{-1}$. It seems difficult to attain high-performance TFTs with a $\mathrm{ZnO}$ based active layer without the Indium element. Therefore, it is necessary to develop a new semiconductor material system suitable for an active layer in TFTs.

Lanthanum hexaboride $\left(\mathrm{LaB}_{6}\right)$ is a known functional ceramic material in the photoelectric field due to its high melting temperature, excellent chemical stability, and high hardness [24-27]. Furthermore, La is relatively abundant in the earth's crust with an annual output of 12,500 t compared to the In with an annual output of $75 \mathrm{t}$ and Ga with an annual output of $30 \mathrm{t}$. In and Ga are limited resources and becoming rarer, so the relatively rich content in the earth's crust means a lower price. Therefore, $\mathrm{LaB}_{\mathrm{x}}$ is cheaper than $\mathrm{In}_{2} \mathrm{O}_{3}$ based material for an active layer in TFTs. Considering the physical properties and cost, there is a great potential for $\mathrm{LaB}_{6}$ materials in the semiconductor field. Conventionally, $\mathrm{LaB}_{6}$ is widely used as cathode emission material $[28,29]$. So far, there is no report about its application in the TFTs field.

In our work, we report the fabrication and performance of TFTs that use compounds with lanthanum and the main family element Boron $\left(\mathrm{LaB}_{\mathrm{x}}\right)$ for the active layer. This is the first time to use $\mathrm{LaB}_{\mathrm{x}}$ thin film as the channel materials in TFTs. The LaB - TFTs exhibited obvious field-effect characteristics. The structure and performance of $\mathrm{LaB}_{\mathrm{x}}$ thin films were investigated by $\mathrm{X}$-ray photoelectron spectroscopy (XPS), X-ray diffraction (XRD), and UV-Visible spectrometer. Compared to the TFTs with ZnO-TFTs with the In element, the outstanding advantages of $\mathrm{LaB}_{\mathrm{x}}$-TFTs include the following: the cost of $\mathrm{LaB}_{6}$ is relatively cheap due to the abundant content of La in the earth crust, which is helpful for reducing the manufacturing cost and the stable chemical properties of $\mathrm{LaB}_{6}$, which is beneficial for high-stability devices. Additionally, the $\mathrm{LaB}_{6}$ has a low coefficient of expansion close to zero, so the stress between $\mathrm{LaB}_{6}$ and adjacent films is low and it is easy to attain high-stability flexible devices. Therefore, it may provide a new choice for channel materials in TFTs.

\section{Experimental}

The $\mathrm{LaB}_{\mathrm{x}}$-TFTs were fabricated with a top contact configuration (see Figure 1) by using a heavily doped n-type silicon wafer with a $300 \mathrm{~nm}$ thick layer of thermally oxidized $\mathrm{SiO}_{2}\left(11.4 \mathrm{nF} / \mathrm{cm}^{2}\right)$, which serves as the gate electrode and gate insulator, respectively. The wafers were cleaned in an ultrasonic bath with acetone, de-ionized water, detergent, de-ionized water, and isopropanol for $10 \mathrm{~min}$ in sequence. The $\mathrm{LaB}_{\mathrm{x}}$ thin films with a thickness of $40 \mathrm{~nm}$ (optimized thickness) were deposited on the silicon wafer by DC magnetron sputtering with $\mathrm{LaB}_{6}$ target in a pure argon atmosphere with a flow of $25 \mathrm{sccm}$ and patterned by a shadow mask with an area of $500 \mu \mathrm{m} \times 800 \mu \mathrm{m}$. For the source/drain electrodes, 380-nm-layer of ITO was sputtered through a shadow mask defining a channel width/length (W/L) of 300/300 $\mu \mathrm{m}$. The whole preparation process was completed at room temperature. We compared the device A to device $\mathrm{B}$ and made a detailed investigation on the different electrical performances between device A and B. In this scenario, the only difference between device $A$ and $B$ is that the $\mathrm{LaB}_{\mathrm{x}}$ channel layer was prepared under different working pressure. For device $A$, the $\mathrm{LaB}_{\mathrm{x}}$ thin film was deposited in pure argon atmosphere with a flow rate of $25 \mathrm{sccm}$ under 
a working pressure of $0.25 \mathrm{~Pa}$. At the same time, the $\mathrm{LaB}_{\mathrm{x}}$ thin film was deposited under a working pressure of 3.8 Pa for device B.

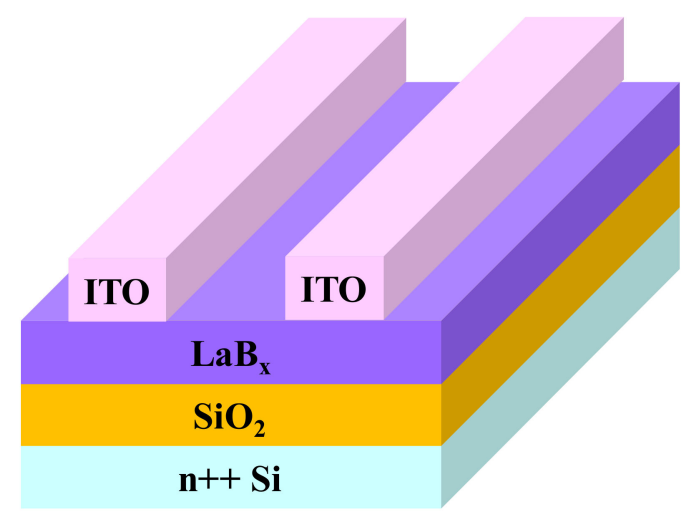

Figure 1. The schematic structure of $\mathrm{LaB}_{\mathrm{x}}-\mathrm{TFT}$.

\section{Results and Discussion}

\subsection{Electrical Properties}

Figure 2a,b show the output curves for $\mathrm{LaB}_{\mathrm{x}}$ TFTs fabricated under the different working pressure of $0.25 \mathrm{~Pa}$ and $3.8 \mathrm{~Pa}$, respectively. Both device $\mathrm{A}$ and $\mathrm{B}$ exhibited strongly-saturated output characteristics. Additionally, device A exhibited a larger output current than device B in a saturation region. The comparison between the transfer curves for device A and B is shown in Figure 2c, respectively. The corresponding properties were summarized in Table 1. Device B exhibited a poor electrical performance with a saturation mobility $\left(\mu_{\text {sat }}\right)$ of $0.13 \mathrm{~cm}^{2} \cdot \mathrm{V}^{-1} \cdot \mathrm{s}^{-1}$, a subthreshold swing (SS) of $0.89 \mathrm{~V}$, a negative turn-on voltage $\left(V_{\text {on }}\right)$ of $-5.31 \mathrm{~V}$, a negative threshold voltage $\left(V_{T}\right)$ of $-2.51 \mathrm{~V}$, and a current on/off $\left(I_{o n} / I_{o f f}\right)$ larger than $10^{3}$. At the same time, device A exhibited a relative satisfactory electrical performance with a higher $\mu_{\text {sat }}$ of $0.44 \mathrm{~cm}^{2} \cdot \mathrm{V}^{-1} \cdot \mathrm{s}^{-1}$, a lower $S S$ of $0.26 \mathrm{~V} /$ decade, a $V_{\text {on }}$ of $-0.44 \mathrm{~V}$, a $V_{T}$ of $-2.27 \mathrm{~V}$, and a $I_{o n} / I_{\text {off }}$ ratio larger than $10^{4}$.
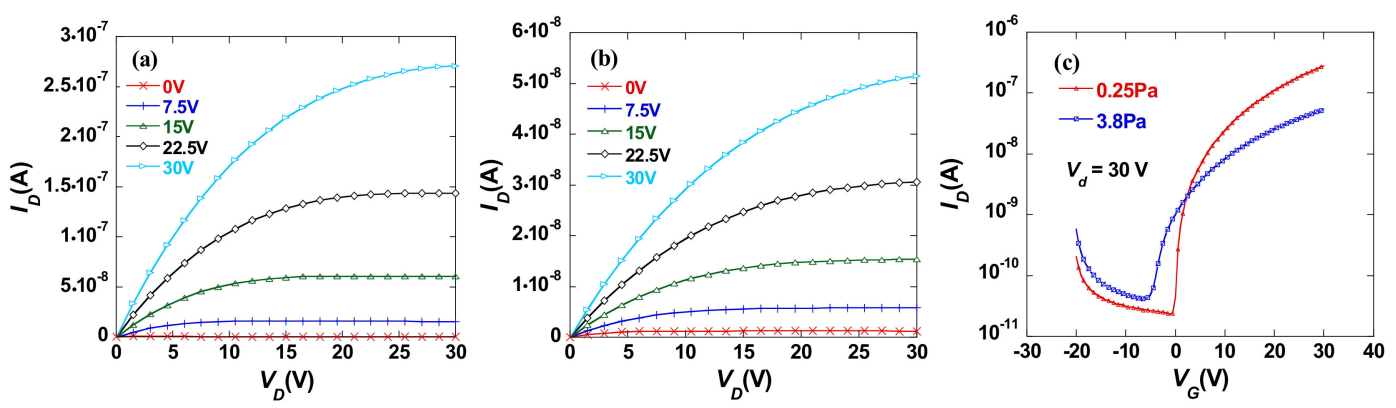

Figure 2. Output curves for device A (a) and device B (b). (c) Transfer curves for device A and device B. (Device $\mathrm{A}: \mathrm{LaB}_{\mathrm{x}}$ active layer was prepared in pure argon atmosphere with a flow rate of $25 \mathrm{sccm}$ under a working pressure of $0.25 \mathrm{~Pa}$. Device $\mathrm{B}$ : $\mathrm{LaB}_{\mathrm{x}}$ active layer was prepared in pure argon atmosphere with a flow rate of $25 \mathrm{sccm}$ under a working pressure of $3.8 \mathrm{~Pa}$ ).

Table 1. Comparison of device properties for device A and B.

\begin{tabular}{cccccc}
\hline Device Number & $\mu /\left(\mathrm{cm}^{\mathbf{2}} \cdot \mathrm{V}^{-\mathbf{1}} \cdot \mathbf{s}^{-\mathbf{1}}\right)$ & $\boldsymbol{I}_{\text {on } / \text { off }}$ & $V_{\text {on }} /(\mathrm{V})$ & $V_{T} /(\mathrm{V})$ & $s /(\mathrm{V} /$ decade $)$ \\
\hline Device A & 0.44 & $1.24 \times 10^{4}$ & -0.44 & 2.27 & 0.26 \\
Device B & 0.13 & $1.22 \times 10^{3}$ & -5.31 & -2.51 & 0.89 \\
\hline
\end{tabular}


The significant difference between device A and B was mainly ascribed to the different chemical structure and atom ratio for $\mathrm{La} / \mathrm{B}$ under a different working pressure [30,31]. For $\mathrm{LaB}_{\mathrm{x}}$ film, the working pressure plays a very important role in the deposition process. Zhao et al. [32] pointed out that $\mathrm{LaB}_{6}$ thin films, which were deposited at $1.0 \mathrm{~Pa}$, have a higher degree of crystalline structure and superior physical properties in comparison with the other films. Hu et al. [33] also reported that argon pressure strongly influenced the condensing particles' kinetic energy clearly by affecting the scattering processes of sputtered energetic particles and $\mathrm{LaB}_{6}$ film deposited at $1.0 \mathrm{~Pa}$ showed a higher crystallinity degree. However, the optimal conditions are not applicable to $\mathrm{LaB}_{\mathrm{x}}$ films in this work, which can be used as an active layer for TFTs. It's noted that the huge difference of atomic weight between La and B is extremely large. For the La atom, the atomic weight is 138.9 while, for the B atom, the atomic weight is only 10.8. This means that the scattering probability of those atoms in discharge space by Ar atoms is very different from each other. The scattering of La atoms is small and La atoms are relatively easy to place at the substrate. On the other hand, B atoms are likely to be scattered by Ar. Therefore, some of them will arrive at the substrate level but some will be deposited at the chamber wall or evacuated by the vacuum pump. This implies that the La/B stoichiometric ratio of $\mathrm{LaB}_{\mathrm{x}}$ film will be changed when deposited under different working pressures. The structure of $\mathrm{LaB}_{6}$ is similar to the that of $\mathrm{CsCl}$, which exhibits a body centered cubic shape [34]. The difference is that the $\mathrm{B}_{6}$ octahedral clusters occupy the position of the $\mathrm{Cl}$ atom and the La atom occupies the position of the $\mathrm{Cs}$ atom. To keep the stability of the $\mathrm{B}_{6}$ octahedral network, two electrons are needed. So the La atom with three electrons in the outermost electron orbital will be electronically spared and the extra electron will be free to move around the La atom. In other words, the electrical properties of $\mathrm{LaB}_{\mathrm{x}}$ thin film will be largely dependent on the chemical structure and the ratio of $\mathrm{La}$ and $\mathrm{B}$. It is reasonable to suppose that the free electrons will increase with the increase of the La/B stoichiometric ratios. However, the resistivity (carrier concentration or mobility) is nonlinear with the La/B stoichiometric ratios because it is also affected by the degree of crystallization and the grain boundary scattering in addition to the La/B stoichiometric ratios [33]. To explain the different properties for TFTs with the $\mathrm{LaB}_{\mathrm{x}}$ active layer prepared under different working pressures, the measurement of XPS, XRD, and UV-visible spectrometer were performed.

\subsection{XPS Measurement}

In order to figure out the composition change of $\mathrm{LaB}_{\mathrm{x}}$ thin film deposited under different working pressures, the XPS measurement was performed. The 300-nm-thick $\mathrm{LaB}_{\mathrm{x}}$ thin film samples were prepared on silicon substrate by magnetron sputtering with $\mathrm{LaB}_{6}$ ceramic target. The $\mathrm{LaB}_{\mathrm{x}}$ thin film samples measured for XRD were prepared under the same conditions. Sample A and sample B denoted for the 300-nm-thick $\mathrm{LaB}_{\mathrm{x}}$ film were prepared with a working pressure of $0.25 \mathrm{~Pa}$ and $3.8 \mathrm{~Pa}$, respectively. In addition, the atomic percentage of each element for sample $\mathrm{A}$ and $\mathrm{B}$ were summarized in Table 2. As shown in Table 2, there are nearly identical atom percentages of La for sample A $(14.0 \%)$ and B (15.3\%) while a significant difference of atom percentage happened between sample A (49.58\%) and sample B (36.9\%). The atom ratio of La/B increased from $28.1 \%$ to $41.5 \%$ with the working pressure increased from $0.25 \mathrm{~Pa}$ to $3.8 \mathrm{~Pa}$, which indicates that the relative content of La was increased. This resulted in more free electrons in $\mathrm{LaB}_{\mathrm{x}}$ thin film. Additionally, this is consistent with the transfer characteristics shown in Figure $2 \mathrm{c}$ where the $\mathrm{LaB}_{\mathrm{x}}$ TFT prepared under the working pressure of $3.8 \mathrm{~Pa}$ exhibited a more negative threshold voltage. In addition, the relatively small on-current may be ascribed to the carrier scattering with the increase in carrier concentration. 
Table 2. The atomic percentage of each element for the $\mathrm{LaB}_{\mathrm{x}}$ thin films deposited under different working pressure. (Sample A: a $300-\mathrm{nm} \mathrm{LaB}_{\mathrm{x}}$ was prepared on silicon substrate by magnetron sputtering with a working pressure of $0.25 \mathrm{~Pa}$. Sample B: a $300-\mathrm{nm} \mathrm{LaB}$ was prepared on silicon substrate by magnetron sputtering with a working pressure of $3.8 \mathrm{~Pa}$ ).

\begin{tabular}{ccccc}
\hline Sample Number & La/at $\%$ & B/at $\%$ & O/at $\%$ & La/B \\
\hline Sample A & 14.0 & 49.8 & 36.2 & $28.1 \%$ \\
Sample B & 15.3 & 36.9 & 47.8 & $41.5 \%$ \\
\hline
\end{tabular}

\subsection{XRD Patterns}

The crystal structure of $\mathrm{LaB}_{\mathrm{x}}$ thin films deposited under different working pressures were investigated by using XRD, which is shown in Figure 3. It is easy to find that the $\mathrm{LaB}_{x}$ thin films prepared under different working pressures exhibited obvious crystalline. However, it is noted that we could not match the acquired diffraction patterns to the standard diffraction patterns for $\mathrm{LaB}_{6}$. This difficulty can be accounted for by using the following two reasons [35]. First, there is a large thermal mismatch between the $\mathrm{LaB}_{6}$ thin film and the $\mathrm{Si}$ substrate. The thermal expansion coefficients are $6.0 \times 10^{-6} \mathrm{~K}^{-1}$ for $\mathrm{LaB}_{6}$ versus $2.6 \times 10^{-6} \mathrm{~K}^{-1}$ for $\mathrm{Si}$ and the difference can induce thermal stress in thin films and shift the patterns. Second, due to the Ar implantation, film deposited by sputtering usually has additional problems such as the deviation in the stoichiometric ratio, the defect state's creation and structural change, which result in the mismatch between the acquired diffraction patterns and reference patterns.

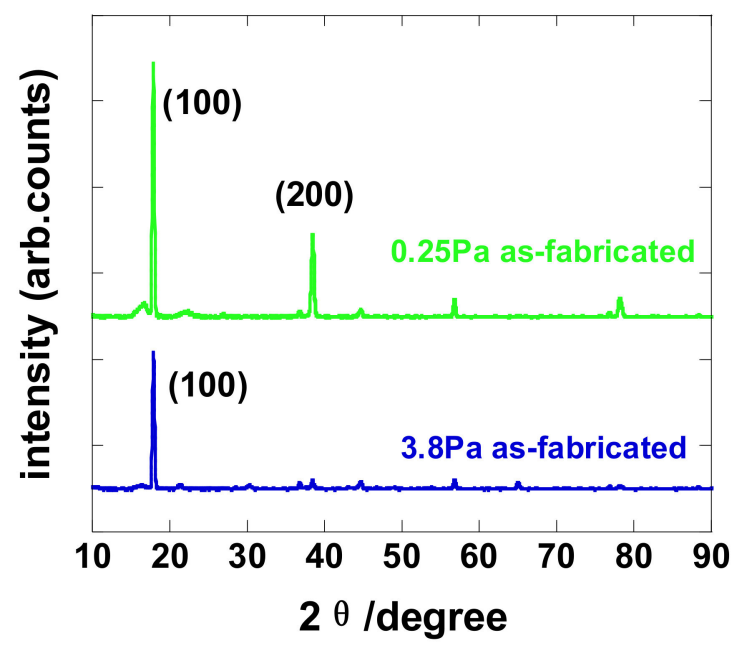

Figure 3. XRD patterns of $\mathrm{LaB}_{\mathrm{x}}$ thin films prepared under different working pressure. (300 $\mathrm{nm}$ on silicon substrate).

\subsection{Optical Gap}

To evaluate the optical bandgap energy $\left(E_{\text {opt }}\right)$, the UV-Visible light absorption spectrum was measured. The 40-nm-thick $\mathrm{LaB}_{\mathrm{x}}$ thin film sample was prepared on quartz glass by magnetron sputtering under a working pressure of $0.25 \mathrm{~Pa}$. The absorption spectrum for $\mathrm{LaB}_{\mathrm{x}}$ thin film was shown in Figure 4. The Tauc model $[36,37]$ indicates the relationship between the photon energy $(h v)$ and the optical-absorption coefficient $(a)$. Additionally, the plot of $(a h v)^{1 / 2}$ vs. photon energy was shown in the inset in Figure 4. The $E_{o p t}$ value can be obtained by extrapolating the linear portion to the photon energy axis in the plot of $(a h v)^{1 / 2}$ vs. photon energy. The $E_{\text {opt }}$ value is calculated to be about $2.28 \mathrm{eV}$. The relatively narrow band gap can lead to smaller activation energies and accumulates the thermally activated carries, which is consistent with the electrical characteristic for $\mathrm{LaB}_{\mathrm{x}} \mathrm{TFT}$ annealed at $400{ }^{\circ} \mathrm{C}$ (not shown). 


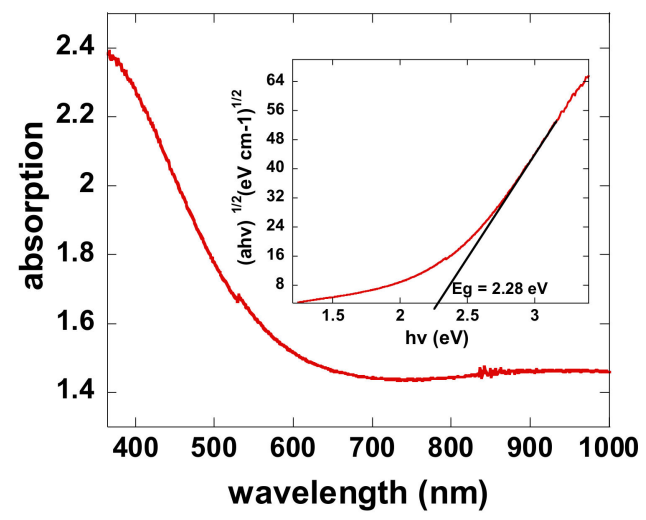

Figure 4. Absorption spectrum of the 40 -nm-thick $\mathrm{LaB}_{\mathrm{x}}$ thin film on quartz glass and the inset shows the plot of $(a h v)^{1 / 2}$ vs. photon energy.

\section{Conclusions}

In conclusion, $\mathrm{LaB}_{\mathrm{x}}$ thin films prepared under different working pressures by $\mathrm{DC}$ magnetron sputtering were investigated as an active layer for TFTs. The element distribution and structural properties of $\mathrm{LaB}_{\mathrm{x}}$ thin films were analyzed by using XPS, XRD, and UV-visible spectrometers. The XPS results demonstrated that the atom ratio for $\mathrm{La} / \mathrm{B}$ was related to the working pressure during the sputtering process and enhanced with the increase in the working pressure. The XRD results showed that the $\mathrm{LaB}_{\mathrm{x}}$ thin film was polycrystalline. According to the absorption spectrum, the $E_{\text {opt }}$ value was calculated to be about $2.28 \mathrm{eV}$ from the plot of $(a h v)^{1 / 2}$ vs. photon energy. The room-temperature fabricated $\mathrm{LaB}_{\mathrm{x}}-\mathrm{TFT}$ exhibited a $\mu_{\text {sat }}$ of $0.44 \mathrm{~cm}^{2} \cdot \mathrm{V}^{-1} \cdot \mathrm{s}^{-1}$, a $S S$ of $0.26 \mathrm{~V} /$ decade, and an $I_{\text {on }} / I_{\text {off }}$ ratio larger than $10^{4}$. The room-temperature processes without intentionally annealing steps show a great potential for the applications in the flexible displays. The $\mathrm{LaB}_{\mathrm{x}}$ may be a new choice for the channel materials in TFTs.

Author Contributions: P.X., J.Y., and B.L. conceived the idea. P.X. and J.H. performed the TFT fabrication and test. P.X., T.D., J.H., and B.L. wrote the manuscript. J.X., D.L., J.Y., and B.L. revised the manuscript. All authors discussed the results and reviewed the manuscript.

Funding: This research was funded by the financial support from the Scientific Research Starting Foundation of Foshan University (Grant No. Gg040926, 040973), the Foshan Science and Technology Innovation Special Funds (Grant No. 2017EZ100111), the National Natural Science Foundation of China (Grant Nos. 61575041, 61704034), the key Platforms and Research Projects of Department of Education of Guangdong Province (Grant No. 2016KTSCX034), and the Science and Technology Planning Project of Guangdong Province (2016B010113004).

Conflicts of Interest: The authors declare no conflict of interest.

\section{References}

1. Mativenga, M.; Geng, D.; Kim, B.; Jang, J. Fully transparent and rollable electronics. ACS Appl. Mater. Interfaces 2015, 7, 1578-1585. [CrossRef] [PubMed]

2. Xu, L.H.; Ou, Q.D.; Li, Y.Q.; Zhang, Y.B.; Zhao, X.D.; Xiang, H.Y.; Chen, J.D.; Zhou, L.; Lee, S.T.; Tang, J.X. Microcavity-free broadband light outcoupling enhancement in flexible organic light-emitting diodes with nanostructured transparent metal-dielectric composite electrodes. ACS Nano 2015, 10, 1625. [CrossRef] [PubMed]

3. Zheng, Z.; Zeng, Y.; Yao, R.; Fang, Z.; Zhang, H.; Hu, S.; Li, X.; Ning, H.; Peng, J.; Xie, W.; et al. All-sputtered, flexible, bottom-gate IGZO/ $\mathrm{Al}_{2} \mathrm{O}_{3}$ bi-layer thin film transistors on PEN fabricated by a fully room temperature process. J. Mater. Chem. C 2017, 5, 7043-7050. [CrossRef]

4. Gleskova, H.; Wagner, S.; Soboyejo, W.; Suo, Z. Electrical response of amorphous silicon thin-film transistors under mechanical strain. J. Appl. Phys. 2002, 92, 6224-6229. [CrossRef]

5. Ryu, J.I.; Choi, Y.J.; Woo, I.K.; Lim, B.C.; Jin, J. High performance a-Si TFT with ITO/n+ ohmic layer using a Ni-silicide. J. Non-Cryst. Solids 2000, 266, 1310-1314. [CrossRef] 
6. Gao, X.; Lin, L.; Liu, Y.; Huang, X. LTPS TFT process on polyimide substrate for flexible AMOLED. J. Disp. Technol. 2015, 11, 666-669. [CrossRef]

7. Lin, C.L.; Chang, W.Y.; Hung, C.C.; Tu, C.D. LTPS-TFT Pixel Circuit to Compensate for OLED Luminance Degradation in Three-Dimensional AMOLED Display. IEEE Electron Device Lett. 2012, 33, 700-702. [CrossRef]

8. Kamiya, T.; Nomura, K.; Hosono, H. Present status of amorphous In-Ga-Zn-O thin-film transistors. Sci. Technol. Adv. Mater. 2010, 11, 044305. [CrossRef] [PubMed]

9. Benwadih, M.; Coppard, R.; Bonrad, K.; Klyszcz, A.; Vuillaume, D. High Mobility Flexible Amorphous IGZO Thin-Film Transistors with a Low Thermal Budget Ultra-Violet Pulsed Light Process. ACS Appl. Mater. Interfaces 2016, 8, 34513-34519. [CrossRef] [PubMed]

10. Hsu, H.; Chang, C.; Cheng, C.; Yu, S.; Su, C.; Su, C. Fully room-temperature IGZO thin film transistors adopting stacked gate dielectrics on flexible polycarbonate substrate. Solid State Electron. 2013, 89, 194-197. [CrossRef]

11. Huang, C.X.; Li, J.; Zhu, W.Q.; Zhang, J.; Jiang, X.; Zhang, Z. A comparison of density of states between InGaZnO based TFTs and InZnO based TFTs. Mol. Cryst. Liq. Cryst. 2017, 651, 221-227. [CrossRef]

12. Xu, H.; Lan, L.; Xu, M.; Zou, J.; Wang, L.; Wang, D.; Peng, J. High performance indium-zinc-oxide thin-film transistors fabricated with a back-channel-etch-technique. Appl. Phys. Lett. 2011, 99, 1117. [CrossRef]

13. Li, M.; Lan, L.; Xu, M.; Xu, H.; Luo, D.; Xiao, P.; Peng, J. Performance improvement of oxide thin-film transistors with a two-step-annealing method. Solid State Electron. 2014, 91, 9-12. [CrossRef]

14. Park, J.S.; Kyeong Jeong, J.; Mo, Y.G.; Kim, H.D.; Kim, C.J. Control of threshold voltage in ZnO-based oxide thin film transistors. Appl. Phys. Lett. 2008, 93, 488-504. [CrossRef]

15. Zhang, L.; Li, J.; Zhang, X.W.; Jiang, X.Y.; Zhang, Z.L. High performance ZnO-thin-film transistor with $\mathrm{Ta}_{2} \mathrm{O}_{5}$ dielectrics fabricated at room temperature. Appl. Phys. Lett. 2009, 95, 072112. [CrossRef]

16. Reyes, P.I.; Ku, C.J.; Duan, Z.; Lu, Y. ZnO thin film transistor immunosensor with high sensitivity and selectivity. Appl. Phys. Lett. 2011, 98, 173702. [CrossRef]

17. Xiao, P.; Lan, L.; Dong, T.; Lin, Z.; Shi, W.; Yao, R.; Zhu, X.; Peng, J. InGaZnO thin-film transistors with back channel modification by organic self-assembled monolayers. Appl. Phys. Lett. 2014, 104, 051607. [CrossRef]

18. Xiao, P.; Lan, L.; Dong, T.; Lin, Z.; Sun, S.; Song, W.; Peng, J. InGaZnO Thin-Film Transistors Modified by Self-Assembled Monolayer with Different Alkyl Chain Length. IEEE Electron Device Lett. 2015, 36, 687-689. [CrossRef]

19. Nomura, K.; Ohta, H.; Takagi, A.; Kamiya, T.; Hirano, M.; Hosono, H. Room-temperature fabrication of transparent flexible thin-film transistors using amorphous oxide semiconductors. Nature 2004, 432, 488-492. [CrossRef] [PubMed]

20. Alston, R.; Iyer, S.; Lewis, J.; Forsythe, E. Investigation of the effects of deposition parameters on indium-free transparent amorphous oxide semiconductor thin-film transistors fabricated at low temperatures for flexible electronic applications. Proc. SPIE Int. Soc. Opt. Eng. 2014, 9005, 126-128.

21. Park, S.Y.; Kim, B.J.; Kim, K.; Kang, M.S.; Lim, K.H.; Myoung, J.M.; Baik, H.K.; Cho, J.H.; Kim, Y.S. Low-Temperature, solution-processed and alkali metal doped $\mathrm{ZnO}$ for high-performance thin-film transistors. Adv. Mater. 2012, 24, 834-838. [CrossRef] [PubMed]

22. Kim, W.S.; Moon, Y.K.; Kim, K.T.; Shin, S.Y.; Ahn, B.D.; Lee, J.H.; Park, J.W. Improvement in the negative bias temperature stability of $\mathrm{ZnO}$ based thin film transistors by $\mathrm{Hf}$ and Sn doping. Thin Solid Films 2011, 519, 6849-6852. [CrossRef]

23. Jang, K.; Park, H.; Jung, S.; Duy, N.V.; Kim, Y.; Cho, J.; Choi, H.; Kwon, T.; Lee, W.; Gong, D.; et al. Optical and electrical properties of 2 wt. $\% \mathrm{Al}_{2} \mathrm{O}_{3}$-doped $\mathrm{ZnO}$ films and characteristics of Al-doped $\mathrm{ZnO}$ thin-film transistors with ultra-thin gate insulators. Thin Solid Films 2010, 518, 2808-2811. [CrossRef]

24. Otani, S.; Nakagawa, H.; Nishi, Y.; Kieda, N. Floating zone growth and high temperature hardness of rare-earth hexaboride crystals: $\mathrm{LaB}_{6}, \mathrm{CeB}_{6}, \mathrm{PrB}_{6}, \mathrm{NdB}_{6}$, and $\mathrm{SmB}_{6}$. J. Solid State Chem. 2000, 154, 238-241. [CrossRef]

25. Zhang, L.; He, W.J.; Tolochko, O.; Polzik, L.; Min, G.H. Morphology characterization and optical properties analysis for nanostructured lanthanum hexaboride powders. Adv. Mater. Res. 2009, 79-82, 107-110. [CrossRef]

26. Gao, R.L.; Min, G.H.; Yu, H.S.; Zheng, S.Q.; Lu, Q.L.; Han, J.D.; Wang, W.T. Fabrication and oxidation behavior of $\mathrm{LaB}_{6}-\mathrm{ZrB}_{2}$ composites. Ceram. Int. 2005, 31, 15-19. [CrossRef]

27. Xu, J.; Min, G.; Hu, L.; Zhao, X.; Yu, H. Dependence of characteristics of $\mathrm{LaB}_{6}$ films on DC magnetron sputtering power. Trans. Nonferr. Met. Soc. China 2009, 19, 952-955. [CrossRef]

28. Dan, M.G.; Watkins, R.M. Compact lanthanum hexaboride hollow cathode. Rev. Sci. Instrum. 2010, 81, 299. 
29. Dan, M.G.; Watkins, R.M.; Jameson, K.K. LaB 6 Hollow Cathodes for Ion and Hall Thrusters. J. Propul. Power 2007, 23, 552-558.

30. Kinbara, A.; Nakano, T.; Kobayashi, A.; Baba, S.; Kajiwara, T. LaB L $_{\mathrm{x}}$ thin films prepared by magnetron sputtering. Appl. Surf. Sci. 1993, 70-71, 742-745. [CrossRef]

31. Oks, E.M.; Anders, A. Boron-rich plasma by high power impulse magnetron sputtering of lanthanum hexaboride. J. Appl. Phys. 2012, 112, 35. [CrossRef]

32. Zhao, X.H.; Min, G.H.; Xu, J.; Lin, J. The influence of argon pressure on the structural and physical properties of $\mathrm{LaB}_{6}$ Films. Appl. Mech. Mater. 2011, 55-57, 1436-1440. [CrossRef]

33. Hu, L.J.; Zhang, L.; Zhao, G.Q.; Lin, J.; Min, G.H. Effect of argon pressure on the structure and resistivity of DC magnetron sputtered $\mathrm{LaB}_{6}$ films. Appl. Mech. Mater. 2013, 303-306, 2519-2523. [CrossRef]

34. Storms, E.K.; Mueller, B.A. A study of surface stoichiometry and thermionic emission using LaB 6 . J. Appl. Phys. 1979, 50, 3691-3698. [CrossRef]

35. Craciun, V.; Craciun, D. Pulsed laser deposition of crystalline $\mathrm{LaB}_{6}$ thin films. Appl. Surf. Sci. 2005, 247, $384-389$. [CrossRef]

36. Tan, S.T.; Chen, B.J.; Sun, X.W.; Fan, W.J.; Kwok, H.S.; Zhang, X.H.; Chua, S.J. Blueshift of optical band gap in $\mathrm{ZnO}$ thin films grown by metal-organic chemical-vapor deposition. J. Appl. Phys. 2005, 98, 1897. [CrossRef]

37. Xiao, P.; Dong, T.; Lan, L.; Lin, Z.; Song, W.; Luo, D.; Xu, M.; Peng, J. High-mobility ZrInO thin-film transistor prepared by an all-DC-sputtering method at room temperature. Sci. Rep. 2016, 6, 25000. [CrossRef] [PubMed]

Sample Availability: Samples of the compounds $\left(\mathrm{LaB}_{6}\right.$ targets) are available from the authors. 